\title{
Mgr Ignace Bourget et les décorations papales de Lafontaine, Wilson et Viger
}

Volume 6, numéro 1, juin 1952

URI : https://id.erudit.org/iderudit/301505ar

DOI : https://doi.org/10.7202/301505ar

Aller au sommaire du numéro

Éditeur(s)

Institut d'histoire de l'Amérique française

ISSN

0035-2357 (imprimé)

1492-1383 (numérique)

Découvrir la revue

\section{Citer ce document}

(1952). Mgr Ignace Bourget et les décorations papales de Lafontaine, Wilson et Viger. Revue d'histoire de l'Amérique française, 6(1), 110-111.

https://doi.org/10.7202/301505ar d'utilisation que vous pouvez consulter en ligne.

https://apropos.erudit.org/fr/usagers/politique-dutilisation/ 


\title{
DOCUMENTS INÉDITS
}

\author{
I \\ MGR IGNACE BOURGET ET LES DÉCORATIONS \\ PAPALES DE LAFONTAINE, WILSON ET VIGER* \\ [ Rome ], Du Quirinal \\ le 11 janvier 1855
}

\section{A Mgr Bedini, Archevêque de Thèbes et Nonce au Brésil.}

Votre Excellence a daigné m'informer que Sa Sainteté avait l'extrême bonté de têmoigner, par quelque faveur particulière, la satisfaction qu'Elle avait éprouvée en apprenant les religieuses ovations, faites au Canada, en l'honneur du St-Siège, dans la personne de son Représentant.

Je demeure tout confus d'une pareille attention de Sa Sainteté; et je dois de nouveau protester à Votre Excellence que le Canada a été trop honoré de la Visite qu'elle a bien voulu lui faire, et qu'il s'est trouvé trop heureux de pouvoir saisir cette première occasion, qui lui était ménagée par la Providence, pour rendre au Vicaire de Jésus Christ les respectueux hommages de sa piété filiale autant que pouvait le lui permettre la simplicité de mœurs et d'usages, dont on doit faire nécessairement faire profession dans le nouveau monde. Nous nous en trouvions amplement récompensés, par les abondantes bénédictions que Votre Excellence avait répandues sur son passage, au nom du St Père, et il ne pouvait nous venir à la pensée d'attendre aucune autre faveur.

Mais puisque Sa Sainteté, dans sa bonté paternelle, daigne ajouter à tout cela de nouvelles graces, je me permettrai de faire à Votre Excellence quelques suggestions, dont elle fera l'usage qu'Elle jugera à propos.

* Arshives de la S.C. de la Propagande: série Scritture riferite nei Congressi America Settentrionale vol. 6 (1849-1857), fol. 693-694. (Documents transerits pour la Revue, par le R. P. C)arad Morin, of.m.). 
Le peuple canadien, qui s'est comme levé en masse, pour témoigner de sa profonde vénération pour le St Père, dans la Personne d'un de ses Nonces, se regarderait comme souverainement honoré si, en retour, le chevalier Baron Hyppolite Lafontaine, Grand Jugè du Canada-Est, recevait quelque décoration de la Cour Romaine. Car je crois pouvoir dire ici que c'est aujourd'hui l'homme le plus influent de notre Pays. J'ajoute que cet honorable chef de la Justice est retourné, de Rome à Montréal, le cœur plein de vénération pour la personne sacrée du St Père, à qui il a eu l'honneur insigne d'être présenté.

La ville de Montréal qui a aussi fait des démonstrations solennelles, pour prouver son attachement religieux à la Sainte Eglise Romaine et à son Immortel Pontife, aujourd'hui glorieusement régnant, en fêtant de son mieux Votre Excellence, se regarderait comme grandement récompensée, si quelqu'autre décoration était accordée à l'Honorable Wilson, qui en sa qualité de Maire, eut alors l'honneur de la recevoir, et qui aujourd'hui est Membre du Conseil Législatif de notre Province.

Enfin, Sa Sainteté encouragerait merveilleusement la science archéologique, dans notre jeune pays et couronnerait les immenses travaux et sacrifices de notre archéologue Canadien, si elle daignait accorder quelque décoration particulière à Son Honneur Mr Jacques Viger, premier Maire de Montréal, dont Votre Excellence connaît le mérite et les vertus. La Religion chez nous, encore plus que la Patrie, aura à profiter des recherches que cet infatigable archéologue a faites de nos antiquités. Car notre pays ayant été établi, il y a environ deux siècles, dans l'unique vue de propager la foi catholique, dans cette partie du nouveau monde, et d'y répandre principalement la connaissance et la gloire de la B.V. Marie, Immaculée dans sa Conception, nos Monuments antiques sont presque tous religieux. Voilà pourquoi les prodigieuses compilations de Mr Jacques Viger sont presque entièrement à l'avantage de la Religion. Votre Excellence en a un petit échantillon ${ }^{1}$ entre ses mains. Aussi doit-elle beaucoup à ce religieux citoyen, d'autant plus méritant qu'il est plus désintéressé.

Votre Excellence voudra bien me pardonner, dans sa grande indulgence, ces suggestions et me croire, avec un profond respect, son très humble et très dévoué Serviteur.

Du Quirinal, le 11 janvier 1855.

(signê) $†$ Ig. Ev. de Montréal.

1. Il s'agit d'un dépliant sur les travaux de Jacques Viger, extrait du Répertoire national (1848), dont un exemplaire se trouve aux ff. 695-696 du volume susdit de la Propagande. 